\title{
Environmental Virtues and Environmental Justice
}

\begin{abstract}
This essay provides a critical analysis of the application of environmental virtue ethics (EVE) to environmental justice. By environmental justice I refer to the concern that many poor and nonwhite communities bear a disproportionate burden of risk of exposure to environmental hazards compared to white and/or economically higher class communities. The most common applied ethical response to this concern-that is, to environmental injustice-is the call for an expanded application of human rights, such as requirements for clean air and water. The virtue-oriented approach can be made consistent with such calls, but there are broader applications as well that generate unique strategies for moral responsiveness and for expanding the role of moral philosophers in civic affairs. ${ }^{1}$
\end{abstract}

Introduction

As recent literature demonstrates, the virtue ethical approach in environmental ethics continues to develop in sophistication and overall coherence. Much remains to be determined, however, with respect to the application of environmental virtue ethics (EVE) and what kind of fruit will be borne of an approach that recommends a fundamental orientation (if not reorientation) of moral thinking in terms of virtues (and related dispositional language) to confront environmental issues. In fact, it may be the case that so much is still unsettled at the theoretical level that the horizon for EVE's application is simply too far off. This putative uncertain state of affairs in environmental virtue ethics has prompted one author to insert the following caveat in a recent paper: "the theoretical base for environmental virtue ethics is in a state of ferment and rich development, and until we have an adequate theoretical base [in environmental virtue ethics], applications may be flawed or even pernicious" (Swanton 2009). Despite this stern warning not to burn the candle at both ends, I must confess skepticism that a little curious exploration of the application of virtues to environmental considerations will bring down the whole house of cards. Indeed, I am more inclined to think that unless we have a good sense of how environmental virtue ethics might be applicable-even if imperfectly-to the kinds of cases we think ethical theory ought to address, there will be less reason to sustain the kind of theoretical refinement that is taking place today.

One area of ethical concern toward which EVE has not significantly aimed is environmental justice. ${ }^{2}$ By environmental justice, I refer in the broad sense to the social

\footnotetext{
${ }^{1}$ Earlier versions of this paper were presented to the students and faculty in the environmental ethics program at the University of North Texas and at the Seventh Annual Meeting on Environmental Philosophy in Allenspark, Colorado.

${ }^{2}$ The environmental justice literature is certainly hospitable to virtue discourse. For example, Kristin ShraderFrechette, who otherwise defends a prima facie duty ethical approach to meet the demands of environmental justice, frequently turns to virtues to add texture to her argument. In one passage in which she criticizes industry victimblaming tactics, she faults private interests who use this strategy for their lack of compassion. She writes, "Besides, virtuous people show compassion, reserve judgment, and assume they are not privy to all the factors responsible for wrong choices" (Shrader-Frechette 2007, p. 107).
} 
movement, particularly in the United States, that has called for political responsiveness to environmental hazards that have disproportionately exposed economically poor and nonwhite communities to toxic risk. The standpoint of this movement is captured by the following claim from the United Church of Christ's report Toxic Wastes and Race at Twenty 1987-2007:

People of color and persons of low socioeconomic status are still disproportionately impacted and are particularly concentrated in neighborhoods and communities with the greatest number of facilities. Race continues to be an independent predictor of where hazardous wastes are located, and it is a stronger predictor than income, education and other socioeconomic indicators. People of color now comprise a majority in neighborhoods with commercial hazardous waste facilities, and much larger (more than two thirds) majorities can be found in neighborhoods with clustered facilities. African Americans, Hispanics/Latinos and Asian Americans/Pacific Islanders alike are disproportionately burdened by hazardous wastes in the U.S. (Bullard et al 2007). ${ }^{3}$

There is little doubt that the virtue ethical approach to environmental ethics is still in development. The fact that the bulk of theoretical work in environmental virtue ethics has been dedicated to testing EVE's cogency for underwriting nonanthropocentrism I think attests to this fact. Or, when authors have attempted to explore EVE's applicability, they've done so more with an eye toward global issues, for example unpacking the virtuous dispositions needed for appropriate responsiveness to longitudinal problems such as anthropogenic climate change or GMO production. ${ }^{4}$ If EVE has not given environmental justice concerns due attention, it may indeed be because virtue-oriented environmental philosophers have been more occupied with theoretical refinement. Alternatively, it may also have a lot to do with the convergence of reflective insights on environmental justice. Once blind spots for ethical inquiry, it is now largely assumed that linkages between race, gender, economic inequality, education, nutrition, health, pollution, public policy, and ecology are of central ethical significance. And as environmentalism has itself arguably transformed into a movement more closely concerned with these issues, there has emerged a coinciding consensus that the inequities of environmental injustice are best addressed by

\footnotetext{
${ }^{3}$ This way of capturing the scale of the movement may not be broad enough. The environmental justice movement is also often described as a global one, where disproportionate risks in exposure to environmental harm can be identified in comparisons between communities in developed and lesser developed countries. Describing the breadth of the movement in this way certainly complicates any effort to identify the kinds of political actions that would ameliorate environmental injustices since these would be expected to vary along with local and national laws. However, to the extent that any ethical response aspires toward universality, as I take the virtue ethical approach to do in its articulation of the ends of the virtues, any virtue ethical response to environmental injustice in one cultural and political situation should be relevant if not directly applicable to others. The broader question of this paper is what the virtue ethical approach can contribute to moral reflection on environmental injustice and how that approach might differ in positive ways from existing deontological and consequentialist solutions to environmental injustice.

${ }^{4}$ Indeed, as I have recently argued elsewhere, EVE appears to be wrestling with many of the same valuetheoretical problems that occupied environmental ethicists in the early years of the field. (See Haught 2010).
} 
the removal of procedural and practical obstacles to more equitable distributive and participatory justice-more ambitious policy proposals notwithstanding. ${ }^{5}$ If virtue ethics has not inserted itself adequately or noticeably into this discussion, it may simply be because the desired moral and political outcomes are already so abundantly clear. Or, to put it differently, working toward more equitable distributive and participatory justice is precisely what the virtuous person would do; consequently, there is simply no controversy to excite the interests of virtue theorists.

If there is something to this line of thought it begins to dissipate against the reality of sustained environmental risk that continues to burden communities across the country and around the globe. Consequently, whatever the reasons for the limited contact between EVE and environmental justice, I think that EVE would benefit from making more contact with it. Similarly, I think there is much that EVE can contribute to environmental justice discourse. Minimally, environmental virtue ethics should provide guidance in removing practical (if not procedural) obstacles to justice. More ambitiously, EVE should be able provide unique insight into the sources of environmental injustice and into the attitudes and beliefs that obstruct appropriate responsiveness to community needs and to values in the more-than-human world.

At least four possibilities emerge for providing such insight and for engaging the intersection between EVE and environmental justice, and it's these four options for contact that I explore in this essay. The first area of contact involves the familiar theoretical project of comparing justifications for the virtues (i.e., their ends) with modern theoretical paradigms for distributive and participatory justice. This area of contact involves the most general assessment of the virtue ethical approach, and it is also the most well-traveled. As a result, I will refrain from providing a highly technical assessment of this approach. Nonetheless, some review of the most promising directions for this approach is warranted. Insofar as environmental justice calls for the removal of obstacles to political participation and to the conditions that allow human beings to live healthy, pollution-free lives, virtue ethical approaches offer especially fertile ground to support those ends. Current political realities, particularly in the United States, entail that distributive and participatory justice will be allocated through a system of rights. Consequently, there is a legitimate theoretical question about whether virtue ethical ends are reducible to principles (e.g., prima facie respect for persons) or concepts (e.g., individualism) within the modern moral traditions that have contributed to our contemporary understanding of rights. Although I think the issue is likely to remain unsettled, if it is true that virtue ethical ends are so reducible, then it seems reasonable to question whether virtue ethics can contribute to the theoretical analysis of environmental justice. One avenue of response is to argue that virtue ethics provides more opportunities to engage theoretically with environmental justice than at the level of political ends. The other three areas of contact discussed in this paper, therefore, will be part of that response.

Thus, a second way to engage environmental justice with EVE is through the call to social and political activism that coincides with living a virtuous life. Whether that call involves the more particular pursuit of environmental justice is the key question for this

\footnotetext{
${ }^{5}$ For example, retroactive environmental reparations for the victims environmental racism. (See for example, Collin and Collin 2005).
} 
approach, and I raise the question whether the environmental virtues can be disentangled from environmentally political ends, and whether this is something to worry about.

The third approach opens up the catalog of virtues to determine what virtues are necessary or sufficient for an adequate response to environmental injustice. At this level attention is directed to the effect of each virtue in disposing its possessor to respond to the demands of the world (i.e., values). What I suggest is that some virtues (including intellectual along with moral ones) are critical for making agents sensitive and responsive to the conditions that create and sustain environmental injustice.

Finally, I consider the community-centered implications of virtue-oriented morality that emphasize local forms of moral life. From the perspective of virtue ethics, this orientation entails the presumption that the local has significant (although by no means complete) sway in an agent's moral development and ultimately her possession and expression of virtue. Consequently, virtue discourse must be sensitive to locally informed beliefs about the virtues. Moreover, the virtue approach advises that many problems, especially those that involve overlapping communities, will require agents to confront translational challenges of moral terms across community boundaries. Most important for the present work will be the observation that common to virtue ethics is a respect for the relative autonomy of localized forms of moral discourse. This understanding compensates for moralistic tendencies of well-meaning outsiders by recognizing the significant influence of environmental and cultural conditions on moral development (along with personal and community identity-formation). The upshot of this approach is not the relativistic privileging of the local; moral discourses can indeed be wedded to mistaken beliefs. Rather it is the theoretical protection, coming from EVE, of the common intuition with respect to environmental justice that justice will not be achieved if the people for whom environmental justice is most directly at stake are not given a voice.

Before proceeding to the heart of the discussion, two caveats are in order relative to the scope and content of this paper. The first is a technical point that the main objective of the essay is to map out a research program in virtue ethics and environmental justice. Viewed this way, each section identifies a mode of engagement between the virtue approach and environmental justice that ideally carves out fertile ground for further inquiry. Every section could also certainly benefit from more fine-grained analysis than I provide here. Given these constraints, both self- and context-imposed, my main hope for what follows is that it clarifies and awakens possibilities for invigorating interest in the virtue ethical approach to environmental ethics and its multifaceted engagement with political questions concerning race, class, and the more-than-human world.

The second caveat is more personal. Despite the importance of separating argument from ad hominem, especially in philosophy, it would be irresponsible to engage in discussion of environmental justice without acknowledging that one's own racial, gendered, and economic status factors in subtle or more overt ways in how one approaches the topic. This acknowledgment is particularly important in the present essay to offset (or perhaps elevate for criticism) concerns about my choice of examples in section IV. There, I discuss the lives of local Memphians, people in my own community, who as black Americans are racially different from myself. In my discussion, I describe the choice by local community activities to recognize them as moral and environmental exemplars, for whom a critical aspect of their exemplary status is their racial identification. As a fellow 
Memphian, their lives and actions take on special significance for me. To the extent that they have been able to contribute to the improvement of my community, I share in the benefits their actions bring. I also hold it to be true that race makes a difference in moral and public discourse, maybe especially so in a place like Memphis, Tennessee where racial oppression is so significant a part of its history, and at the time of this writing, a place where voters have elected to surrender their school charter to mitigate longstanding educational injustices resulting from suburban white flight in the county. Consequently, I offer the observation that the choice to single out for praise the environmental accomplishments of black Memphians takes on a special significance for how to think about moral and environmental virtue and in appreciating how we all individually and sometimes collectively occupy places within and outside different virtue discourses. With this observation, unfortunately, comes a vulnerability for my project, exposing my own standing as a white male academic as a target for scrutiny. I suspect this is an inescapable part of our racial discourse today, and I confess that I have no solution for it. We live in a racially traumatized world. My hope, however, is that the following essay illustrates how theorizing about the virtues requires a range of reflection-from the highly general to the narrowly particular-on the meaning, possession, and application of the virtues, and that if this approach opens us to certain vulnerabilities, that they are important for empowering all of us to right the wrongs of environmental justice wherever they occur.

\section{Are environmental (justice) virtues derived from rights?}

It is a familiar question for virtue ethics whether the virtues (e.g., generosity, compassion, humility, self-respect, etc.) are really derivatives of simpler formulations of right action. So understood, a virtue would be a habit that disposes one to act in a certain way, and it is a virtue because that way of acting is consistent with respecting the autonomy and dignity of oneself and others and/or of promoting the common good. Moreover, so understood, since virtues are habits of character, but because they are only mere habits, it would be theoretically more efficient to eliminate them from the most important efforts in moral theory, which involve refining our most rationally defensible formulations of right actions. To summarize crudely, on this view, $x$ is a virtue because $x$ is consistent with deontological or utilitarian formulations of right actions.

I bring this up not because I am (presently) interested in engaging with this line of critique, but because I suspect that it will necessarily come up when the virtue ethical approach to morality is brought into contact with environmental justice. The reason for this suspicion is that as the environmental justice movement has acquired an academic voice, the history of that development has been to call for more robust and more consistent applications of individual rights and entitlements, and these find their own robust theoretical defense in modern political theory, particularly political liberalism. Consider Kristin Shrader-Frechette's so-called principle of prima facie political equality:

To correct problems of environmental justice, it will be necessary to improve the principles and practices of distributive justice-[e.g.,] equal apportionment of social benefits and burdens, such as toxic waste dumps. It 
also will be necessary to reform the principles and practices of participative justice-[e.g.,] equal rights to self-determination in societal decision making (Shrader-Frechette, 2002, p. 24).

If virtues are eliminable-i.e., from moral theory as opposed to moral life and practicethen Shrader-Frechette's principle helps to explain why because they do not appear to be necessary as part of our understanding of distributive justice or political equality. Presumably, those ends are explicable in terms of human interests, needs, preferences, etc. Nor does it seem necessary to call upon the virtues to achieve such ends (even though it might be nice). Assuming that calls for distributive justice and greater political equality are rationally defensible, who cares if it's virtuous to achieve them? What matters is that it's right.

The virtue ethical response to such critique is varied. Although this is not the place to catalog the range of responses, it is worth dwelling on the general sense common to virtue ethics that moral life is richer than what is captured in a rationally tight maxim, and that moral theory must be adequate to moral life if it is to be relevant. The other three areas of contact that I explore in this paper try to capture that intuition. Nonetheless, there are some relatively straightforward ways to show how a virtue ethicist would address something like Shrader-Frechette's principle directly, and these responses call into question if not contravene the claim that virtues are derived from individual rights.

Within contemporary virtue ethics, Aristotelian eudaimonistic approaches appear to be especially well-suited to the aims of environmental justice. Common to these approaches is the recognition of universals within the human situation that clarify the ends that justify the virtues. For Martha Nussbaum, these universals reflect the fundamental value in having the capacity "to choose and fashion a life" (Nussbaum 1999). On Nussbaum's view, these universals are not so sharply defined so as to restrict variance among virtues and virtue language in different communities. Nonetheless, they are persistent enough that agents will work to support them wherever they are and within the prevailing social and political circumstances in which they live. "This is how the Aristotelian approach works-hanging on to a general (and open-ended) picture of human life, its needs and possibilities, but at every stage immersing itself in the concrete circumstances of history and culture" (Nussbaum 1993). Thus, Nussbaum is willing to link this view to the "vision of liberalism" as "the vision of a beautiful, rich, and difficult world, in which a community of persons regard one another as free and equal but also as finite and needy-and therefore strive to arrange their relations on terms of justice and liberty" (Nussbaum 1999).

Nussbaum's approach leads her to suggest a list of common features of our humanity that support the virtues, a list that includes considerations of human mortality, embodiment, sensations of pleasure and pain, cognition, practical reason, early infant development, fellowship and affiliation with other humans, and humor (Nussbaum 1993). A similar list of universals can be found in the Aristotelian approach advanced by Rosalind Hursthouse and refined to accommodate environmental virtue by Ronald Sandler. On Sandler's view, 
A human being is ethically good (i.e., virtuous) insofar as she is well fitted with respect to her (i) emotions, (ii) desires, and (iii) actions (from reason and inclination); whether she is thus well fitted is determined by whether these aspects well serve (1) her survival, (2) the continuance of the species, (3) her characteristic freedom from pain and characteristic enjoyment, (4) the good functioning of her social groups, (5) her autonomy, (6) the accumulation of knowledge, and (7) a meaningful life-in the way characteristic of human beings (i.e., in a way that can rightly be seen as good) (Sandler 2007).

For Sandler, then, the virtues are justified by their successful contribution to these ends. In addition, because there are many different situations that determine how these ends are met, virtues are defined by their specific targets. So for example, compassion is likely to contribute to several ends on the eudaimonist's list, but because the targets of compassion are typically other persons, some ends are more pronounced than others, and that can even vary by situation. Compassion in my approach to educating my students may be particularly supportive of 2 and 4 (not to mention my concern for their capacity to experience 5-7). Compassion that moves me to assist my neighbors whose child is injured in an accident is justified for me by 4 but sympathetically extends to concern for several other ends relevant to the lives of my neighbor and their child.

In moral practice, the practice of living a virtuous life, it would be odd if most of the time one had to corroborate one's actions with something like Sandler's or Nussbaum's lists. The point of having such lists, then, is to show how virtues are justified and to serve as reminders that such justifications are important when situations present us with difficult choices or when we disagree about the virtues. But it also important to note that for both Nussbaum and Sandler these justifications do not exhaust what it means to possess this or that virtue. The virtues are not reducible to their ends; indeed, the ends underdetermine the virtues. Thus on the eudaimonist's picture of moral life, the rights-based orientation of environmental justice emphasizes the political means for achieving justice (i.e., rights) that are typical of our present social and political situation and thereby useful for ensuring the conditions for living well. Were our politics different, some other political instrument would presumably be needed to ensure the viability of those conditions, and the relevant virtues would lead the virtuous person to consider using it. It would also make sense that the specific profiles of the virtues and their targets would be adapted for such circumstances. But in those circumstances, as in our own, it would not be correct to conclude that the virtues are reducible to and thereby eliminable relative to the ends of theories of right actions and their correlative theories of rights.

Yet there are alternative approaches to virtue ethics that may undermine any consistency between virtue and environmental justice. It may be thought, for instance, that what triggers the concern that virtues are eliminable relative to calls for rights is the teleological nature of the justifications of the virtues. Because the virtues aim toward particular ends, and more broadly, to one general end of living well, the end is really what matters; the virtues are again mere habits that ought be replaced by rationally defensible propositions of right action. Some virtue ethicists, sensitive to this rendering of the virtues, have elected to question the necessity of teleological justifications altogether. Virtues are 
justified by their admirability (Slote 2001) or their dazzling effects (Swanton 2003) because these traits are characteristic of what is excellent about us, valued by ourselves and our peers, but not necessarily conducive to living well. On the one hand, by loosening the teleological justifications of the virtues, these noneudaimonistic positions also mitigate the prospect that virtues are reducible to ends. On the other hand, if a virtue is justified because it is admirable or dazzling, the consistency between virtue ethics and environmental justice might also disappear. It might turn out that those who scoff at such concerns are more admirable, and those who distract us from ours and others' suffering are more worthy of our emulation than those who endeavor to call our attention to political, economic, and racial injustice. Noneudaimonists, however, typically do not box themselves in so tightly. Virtues require moral communities for them to develop meaning and moral salience. Within moral communities, it is by no means a given that admirability runs out with political celebrity or that an entertainer's ability to distract us from our fears and pains is more precious than a communal sense of what is vitally important. David Hume, to the extent that he was a noneudaimonist, thought that what justifies a virtue is its "agreeableness" or utility to its possessor or others (Hume, Treatise). ${ }^{6}$ But Hume also thought that a virtue is what makes one fit well in society and that virtues will be adapted to individual and social circumstances and needs. The noneudaimonist's resistance to teleology (or to teleological monism) may make it more difficult to adhere it to the rightsbased aims of environmental justice, but by no means is the noneudaimonist's account of virtue necessarily inconsistent with those aims either. And if the virtues, as Hume thought, fit us well to our circumstances and needs, then the virtue-oriented environmental justice theorist is also positioned well enough to draw attention to how much we might need the benefits of distributive and participatory justice.

\section{EVE and the call for social and political activism}

The form of engagement between EVE and environmental justice just discussed describes general conditions for consistency between justifications for the virtues and the aims of environmental justice. As a logical and theoretical value, however, consistency is neither ethically nor politically normative. Consistency settles the question of can, but it is silent on the issue of ought. Moreover, as also suggested by the above discussion, for both contemporary eudaimonists and noneudaimonists, there is widespread agreement that the ends of the virtues underdetermine the targets of the virtues. In other words, the particular profiles of the virtues (i.e., their particular meanings and targets) are permitted and expected to vary across communities. On this pluralistic view, for certain communities, the virtues may be aligned with the aims of environmental justice, but there is no apparent necessity that they do so.

From a methodological standpoint concerning moral theory, these conclusions seem correct. If virtue theories expressly commit agents to hold specific political beliefs, then it seems that something has gone badly wrong philosophically. Indeed, such theories might

\footnotetext{
${ }^{6}$ Swanton argues that a trait can "be a virtue even where it has tendencies to be bad for the possessor in nonutopian universes such as our actual world" (Swanton 2003, p. 20).
} 
stray from philosophy, crossing over into social and political advocacy. Insofar as methodological propriety requires that philosophers avoid advocacy positions in their work, then it might be good practice simply to avoid devoting theoretical resources to political applications and particularly to avoid matching one's theory with the aims of social movements like environmental justice. Even the term of art, "environmental virtue ethics," raises questions of advocacy. And as much as I prefer to use EVE as the term to describe a family of approaches that engage the virtues with environmental ethics, it is noteworthy that authors like Sandler adopt more neutral terminology in their virtue ethical approaches-Sandler consistently refers to his preferred method as the "virtue-oriented approach" to environmental ethics.

Nonetheless, the argument for consistency between virtue ethics and environmental justice suggests that worries about advocacy can be avoided when there is common ground between the ends of the virtues and the ends of environmental justice. In principle, the virtuous person need not be politically involved in the environmental justice movement to support universal calls for distributive and participatory justice. The virtuous life is ostensibly separable from this or that form of political activism. Or is it?

If virtue ethics is not as methodologically pristine compared to utilitarianism or deontology it is in part because much of the ethical work to be done occurs at the level of particular virtues. Virtue ethics expects an agent to be able to explain his or her action in reference to the possession of and targets relative to a particular virtue without also having to specify an account of its ends (although theoretical justifications of the virtues certainly do depend on those ends). There is also the recognition that virtuous agents will be certain sorts of persons, the kinds of persons who will act to ensure that virtuous lives are possible. Consequently, there are virtues that coincide with this description of the virtuous person, virtues that call on agents to respond to the needs of their communities through social and political engagement. Call these civic, social or public virtues, ${ }^{7}$ they are virtues that capture the intuition that the virtuous person is committed, by way of his or her virtues, to contribute to the effort to create and sustain the conditions for virtuous life.

In the environmental virtue ethics literature, such virtues have received recent attention by Phil Cafaro and Brian Treanor. In explicating the virtue of patriotism, Cafaro urges his readers to accept environmental activism as patriotic. Patriotism is a virtue because it sustains communities, has personal benefits for life within a community, and environmentally it expresses "a general concern to protect the land and the people of one's homeland" (Cafaro 2009). Treanor, for his part, bemoans the absence of more explicit calls for social activism in environmental ethics and enjoins his readers to take up the cause as it is consistent with virtue. Treanor also thinks that academic virtue ethics has largely ignored public virtue with the unfortunate outcome "that environmental virtue is frequently seen as (1) a personal preference rather than a requisite component of human flourishing and (2) a matter of individual actions isolated from social engagement" (Treanor 2009).

Both Cafaro and Treanor mount persuasive cases for environmental activism as a political virtue justified by its ability to fit agents well to the demands of the world and to promote human flourishing. Although neither author explicitly addresses environmental

\footnotetext{
${ }^{7}$ Sandler calls them "virtues of environmental activism" (Sandler, 2007, p. 82).
} 
justice, I would suspect that given the promise of the social and ecological benefits that it represents, both would support environmental justice advocacy. Moreover, such advocacy would at least be consistent with their shared sense that more needs to be done to improve our social and environmental circumstances. However, both Cafaro and Treanor appear to conflate the call for activism that stems from the virtues with the content of one's politics, and neither does enough to consider the views of someone who might meet the requirements of patriotism or public virtue but disagrees with the political solutions they see as necessary.

Let me clarify. Treanor is indeed aware that political activism is open to vice, urging us to be on guard against utopianism (although apathy is for Treanor the greater foe of public virtue). Cafaro, for his part, certainly understands that patriotism exposes a society to certain dangers. It will be a challenge, he notes, for agents to avoid the vice of destructive nationalism, for instance. But neither position moves recognizably to consider the possibility that either public virtue or patriotism could entail the advocacy of political ends that are not environmentalist. Does environmental virtue therefore rig the game on the side of environmentalist political ideals?

To see that this question is not simply provoked by my own zealous obsession with fairness, consider the pro-property libertarian-style objection that virtue ethics is itself a veiled form of personal politics that promotes a potentially harmful essentialism with respect to human nature and the ends of the virtues. The libertarian will have a motive to become politically active-especially if he inhabits a world of Cafaro's patriots-because he wants to ensure his right to property is not threatened by his neighbors' obsession with virtue and environmental justice. For the libertarian's motive not to be virtuous, something else about the libertarian has to be demonstrably vicious. One likely candidate is his fundamentalism with respect to property rights. However, we would still need to establish that rights fundamentalism is contrary to virtue, and this may turn out to be difficult, particularly since it is quite conceivable that a virtuous sense of justice will respect the inalienability of property rights.

Of course, it is also precisely because property rights do not necessarily undermine the ends of virtue, and because they are arguably consistent with human flourishing, that the virtue-oriented environmental justice advocate has plenty of ground on which to engage the libertarian, and both can agree that the protection of negative rights and the right to political participation itself are critical to their respective interests. And interestingly, since much of what's at stake in environmental justice concerns the status of the possession and exercise of rights on grounds that a libertarian might tentatively be willing to accept (especially, with respect to property rights and the right to political participation - the social costs for eradicating toxic risk notwithstanding), there is reason to think that the virtue ethicist's call for political activism could sustain an uneasy political alliance between libertarians and environmental justice advocates. Whether libertarian activism is consistent with virtue, however is still unclear.

Between Cafaro and Treanor, Cafaro comes closest to leaving that option open. In his response to Alasdair MacIntyre's worry that patriotism is a "permanent source of moral danger." Patriotism is a danger because it threatens to undermine key universalist components of morality such as impartialism. Against this view, Cafaro defends a virtue ethical particularism, writing, "We may hold robust patriotic commitments while accepting 
that all our practices, all our particular relationships, the meaning of all our values, all our tentative weightings and balancing of those values, and all aspects of our communal narratives, are up for continuous rethinking and renegotiation" (Cafaro 2009). Does this mean that there can be libertarian public virtue? Can there be public virtue that does not take the aims of environmental justice as worthwhile political endeavors?

If Treanor and Cafaro are correct, then the answer to both questions is 'probably not' given the apparent unrevisability of the typical libertarian stance on property rights (and only probably if one accepts the fallibilism of Cafaro's virtuous patriot). Nonetheless, because Cafaro's particularism allows for self-correction, a tentative conclusion can be reached that environmental virtue ethics can support advocacy for environmental justice in political partnership even with those who use the political process for their own distinct (if not virtuous) ends. This conclusion means that the question of game-rigging the virtues on the side of environmental ideals has not gone away. However, the burden of proof appears to shift to the opponents of environmental justice to justify that opposition in terms of an alternative thesis of public virtue.

It may be objected that my worry about game-rigging stems from a thesis of the unity of the virtues. In other words, to possess 'environmental virtue' on my account implies that the pro-property libertarian (or other foe of environmental regulation) would necessarily lack virtue because, even though she might be politically engaged (and thereby possess that virtue), she nonetheless could simultaneously lack virtues like humility or compassion that would entitle her to be called virtuous. Where I think this objection is correct is in drawing attention to the fact that the question of the possession of a virtue is answerable in part from the standpoint of the needs and values of one's moral community. Consequently, the advocate for environmental justice can admire the political engagement of a political adversary despite the fact they disagree on their politics. Having the disposition for civic and political disposition is, all things considered, a good thing for a human being to have because, independently of one's other virtues, it is consistent with many justifiable ends of virtues (see, e.g., Sandler's list of eudaimonistic ends from earlier). However, the environmental justice advocate might also fault her adversary's politics for their lack of compassion, prudence, or humility. My position is not that an agent must be unified in her possession of virtues to hold any particular virtue. However, as I have argued elsewhere, and as I reiterate in the next section, the possession of certain virtues, like humility and compassion, have particular effects for their possessors that make environmental concern meaningful, and their absence in an agent can make all the difference for how far one extends the reach of their aesthetic, moral, and political values (see Haught 2009). ${ }^{8}$

\section{The Profiles of the Virtues}

A related but less controversial way to engage EVE with environmental justice is through the explication of particular virtues, and there are many besides public virtue or

\footnotetext{
${ }^{8}$ I wish to thank Brian Treanor for his correspondence in helping me articulate this insight in the present context.
} 
patriotism that would be relevant to environmental justice related issues. One of the important effects of the possession of any virtue is to prepare its possessor to respond to the world in a particular kind of way. More precisely, virtues put their possessors in position to respond to value, and, in some cases, to prepare agents for new modes of valuing and even to discover new sources of value. For example, in responding to environmental value, virtues such as humility and wonder are especially important, at least in establishing the conditions for such responsiveness. To be humble or to wonder is to be aware of the value of something other than oneself, although in different ways. Those virtues that fit agents well to be receptive to their environments and to the persons, objects, and qualities of those places, will also be important for environmental justice. Especially significant are those virtues, independent of those relevant to the call for political activism, that cultivate awareness of difference, sensitivity to tradition, as well as sympathy, compassion, and a healthy fear of power (a contemporary form of humility). ${ }^{9}$

Possession of these virtues is especially important for those who benefit from existing power structures, and more specifically, who stand to gain from economic and environmental inequities. They're important not because they will sustain economic and racial imbalances but for precisely the opposite reason. These are the virtues that guard not only against racism and sexism but provincialism (and nationalism) and vicious egoism. As Hume and others have observed, however, these kinds of virtues - the ones we would typically associate with justice-will be a hard sell to the hard-hearted, the selfinterested, and the hyper-rational. (Hume, Second Enquiry). They don't offer immediate rewards to their possessors, and many of them moderate against an excessive (if not more immediately rewarding) sense of self-importance, economic and cultural entitlement, and fear of collective action. Moreover, these are virtues that require agents to put their faith in institutions - particularly educational and political - to compensate for individual and collective ignorance, thoughtlessness, and selfishness. More specifically, these are the virtues that compensate for skepticism that communities in our cities and across the country and around the world are really and truly disproportionately burdened with toxic risk because they are nonwhite and not because they are poor, uneducated, or the hapless victims of historical circumstance.

From the standpoint of environmental virtue ethics, these will be defensible virtues. Eudaimonistically, they make their case for supporting the end of human flourishing. Noneudaimonistically, these virtues will already be part of our moral discourse, and they have achieved that status because they fit agents well to respond to the demands of the world. Perhaps, for lack of a better phrase, these are the 'virtues of social contingency' as they reflect an understanding of the circumstantial nature of any particular human being's original position. As virtue catalogs go, this is a list that would begin with conscientiousness, thoughtfulness, and humility with the larger point that failure to possess many of these virtues will likely occlude awareness of the social, economic, and environmental inequities at the roots of environmental injustice.

\footnotetext{
${ }^{9}$ The list of suitable virtues will be long and even then incomplete. It begins with conscientiousness, but more particular virtues will be vital for fleshing out the concept: attentiveness, appreciation, benevolence, care, imagination, empathy, sympathy, neighborliness, friendliness, hospitality, nurturing, maturity, fortitude, and many others. Christine Swanton's Heideggerian virtue of dwelling is very much what I have in mind here (see Swanton 2009).
} 
IV. EVE and the relative autonomy of the local

A few years ago I participated in a panel on religion and ethics at an environmental justice conference in Memphis with Rev. Ralph White of Bloomfield Baptist Church, a church in southwest Memphis. It was the first time I met Rev. White, who I came to learn has been one of the key activists for environmental justice in the Midsouth. Among his more effective civic endeavors was co-founding a neighborhood association in the Riverview community where his church is located. Through this organization (Riverview Community Collaborative) he mobilized campaigns to protect public green spaces and to stop the construction of a nuclear waste incinerator adjacent to the community. ${ }^{10}$ The neighborhood association also established a daycare facility and continues to regularly organize health fairs and children's activities-including an annual fishing rodeo. At our panel discussion, White expressed the desire to make the pursuit of environmental justice a community-based priority as opposed to a policy priority delivered from outsiders (like his fellow speakers on the panel perhaps). Political alliances were fine, he said, but "we have to be willing to pick up a shovel if we want to clean up the neighborhood." The point I wish to draw from White's narrative is relatively simple, but one with an important implication for environmental virtue ethics and its contact with environmental justice. White's comment is a reminder that responsiveness to the demands of the world is rooted in the moral education, language, and the habits of our communities. His church's community is especially accomplished-although by no means in the clear-in responding to threats to its wellbeing and survival. Its success is arguably as much a consequence of community members awakening to their plight and seeing it as something to which they must respond as it is taking whatever help they can get from sympathetic outsiders and the occasional politician to turn attention their way. ${ }^{11}$

I met White again more recently at an awards ceremony held in a neighborhood just north of my campus in midtown Memphis. The occasion was "Blacks Living Green," and White was one of the honorees - along with the county mayor, a teacher, a park ranger, a

\footnotetext{
${ }^{10}$ The company in question was Radiological Assistance, Consulting and Engineering, LLC or "RACE." In 2005, the city of Memphis health department gave RACE a permit to build a low-grade nuclear waste incinerator in South Memphis. A coalition of community organizations (including Riverview Community Collaborative) and advocacy groups successfully halted RACE's plans to site the incinerator in Memphis (Meek 2005).

${ }^{11}$ Of course, the realities of racial politics in Memphis and black experience in Memphis are also undoubtedly embedded within White's comment. Specifically what those realities are for a black Baptist preacher are impossible to glean from one remark. Charles Mills has suggested, however, that environmentalism for blacks in the U.S. cannot be separated from social identification with the fact that "Black relations to nature have always been mediated by white power." More strongly, Mills asserts, "EEnvironmentalism' for blacks has to mean not merely challenging the patterns of waste disposal, but also, in effect, their own status as the racialized refuse, the black trash, of the white body politic." (Mills 2001, p. 89). The position I'm taking in this paper urges that the virtue ethics requires taking such claims seriously, even to the point where there is significant uncertainty about the translatability of local virtues between communities. Nonetheless, both eudaimonistic and even noneudaimonistic approaches to virtue ethics appear to have resources to sustain meaningful dialogue between communities that are otherwise divided by culture, custom, race, and historical and present distributions of power.
} 
forester, a horticulturalist, an artist, a biologist, a community activist, and an entrepreneur - all of whom were present to be recognized for their contributions as "local African American 'green' role models" (Blacks Living Green 2009). The gathering itself was intimate, mostly friends and neighbors, which was somewhat surprising given the number of honorees. The local paper wrote a short article about it. The day passed. So why am I mentioning this? Because whatever the impact of "Blacks Living Green," the effort is an ethical one guided by a practical wisdom that comes from years of seeking to make communities flourish in toxic environments. Few people in Memphis know as much as these honorees do about how to navigate the educational, political, racial, environmental, and spiritual challenges of community life in the area. By utilizing the concept of 'green role model' in introducing these talented people to their neighbors, the event elevated the profile of the values and virtues of local exemplars of environmental virtue.

Earlier I highlighted Treanor's worry that virtue ethics is often too agent-centered at the expense of public virtue, but with exemplars like White and his fellow honorees there is also reason to think that the virtues of one person can be especially important in assisting an entire community in its response to environmental injustice. Their narratives also illuminate another critical feature of virtue ethics significant for environmental justice. In the introduction to her book On Virtue Ethics, Rosalind Hursthouse qualifies her own approach by claiming "that it is a mistake to suppose that ethics can be given any sort of foundation 'from the neutral point of view,'” to which she adds, "ethical thought has to take place within an acquired ethical outlook." (Hursthouse 1999, 20). Swanton makes a similar point in discussing constraints on virtue application:

Apart from creativity and the ability and willingness to test assumptions, beliefs, and understandings, possibly the most important cognitive moral virtue is that of a contextualized, concrete, and non-dichotomized thinking. An abstract formulation of the constraint structure [of virtue] robs it of the richness that makes it possible for a problem to be resolved (Swanton 2003, p. 263).

Among the implications of these observations of the virtue-oriented approach is that virtue ethics is well-suited to be appropriately sensitive to the unique features of environmental problems and the qualities of the agents in the communities that face them. When a company with a bad toxic record attempts to demonstrate its good-neighborliness with donations of school supplies to the neighborhood schools, it is easy to fault the company for acting exploitatively, but it is not an obvious wrongdoing for local schools to accept the donation, especially if the result improves dialogue between community leaders and company directors. It will be important for communities not to sustain conditions that prevent them from flourishing, but what decisions they make will need to be their own, however informed they are by more broadly conceived notions of virtue.

Postscript: Jobs for Philosophers

When I originally started this project, I was motivated in part by a desire to connect the personal with the professional. Within the foregoing discussion, this desire confronts 
the professional and methodological boundary between ethics and advocacy. Beyond the project, the desire springs from my conviction that philosophers can and do serve the communities in which they live and work. In light of what I have so far been able to sketch in this paper two general strategies for defining such service in the context of environmental justice emerge. The first concerns straightforward professional philosophy. Although I only describe this strategy in Section III, the explication of particular virtues promises to be valuable in describing the conditions for effective responsiveness to environmental injustice. Whether these virtues turn out to be thoroughly green ones, such as many in Louke van Wensveen's catalog (Van Wensveen 2000) or more traditional, a careful analysis of the effects of possessing particular virtues by particular agents in particular communities will have philosophical and very likely practical benefits for nonphilosophers interested in orienting their thinking along virtue-oriented lines. As a result, reflections such as those by Cafaro on patriotism, Hill on humility, Welchman on benevolence and loyalty, or Swanton more recently on dwelling all have implications for life on the environmental justice front lines.

The second strategy concerns a practical application of philosophical skill, an area where the role of the philosopher is less certain, but one possibility is to make oneself available to help resolve disputes within communities (over what actions to take in response to a toxic threat) or between communities and other stakeholders, even between communities and their main environmental adversaries. The company in Memphis that sought to elevate its ethical profile by donating pencils to White's Riverview neighborhood schools would arguably benefit from some "virtue ethical counseling." It is conceivable that in many cases disputes are often verbal, and if a dispute concerns different weightings of relative virtues, a philosopher skilled in virtue ethics might help disputants focus on the constraints at work in their respective framing of their practical and ethical priorities. How one inserts oneself in such situations is difficult to determine. At a minimum it would require sensitivity to the relative autonomy of local moral communities, and good communication skills and training in conflict resolution would also be valuable. Inserting oneself in community issues in this way may be challenging (even pernicious), but moral philosophers already good at mapping out the dynamics of various sorts of conflicts are arguably well-positioned to share those insights at the invitation of those in their own communities with most to gain from acquiring them.

Bibliography

“'Blacks Living Green': An Evening with Author Dr. Sharon T. Freeman and Ten Local African American 'Green' Role Models." April 9, 2009. Program bulletin for "Blacks Living Green” awards ceremony. Memphis, TN: Caritas Village. In possession of author.

Bullard, Robert, et al. 2007. Toxic Wastes and Race at Twenty 1987-2007. United Church of Christ.

Cafaro, Philip. 2009. "Patriotism as an Environmental Virtue." Journal of Agricultural and Environmental Ethics 23 (1-2): 185-206. 
Collin, Robin Morris and Robert Collin. 2005. "Environmental Reparations.” In Robert Bullard, ed. The Quest for Environmental Justice: Human Rights and the Politics of Pollution. San Francisco: Sierra Club Books.

Haught, Paul. 2009. "Hume's Knave and Nonanthropocentric Virtues.” Journal of Agricultural and Environmental Ethics 23 (1-2): 129-43.

Hill, T. 1983. "Ideals of Human Excellences and Preserving Natural Environments." Environmental Ethics 5 (3): 211-24.

Hume, D. (1975) An Enquiry Concerning the Principles of Morals. In L.A. Selby-Bigge (Ed.), P.H. Nidditch (Rev., 3rd edition) Hume's Enquiries. Oxford: Clarendon Press.

. (1978) A Treatise of Human Nature. L.A. Selby-Bigge (Ed.), P.H. Nidditch (Rev., 2nd edition). Oxford: Clarendon Press.

Hursthouse Rosalind. 1999. On Virtue Ethics. Oxford.

Meek, Andy. October 11, 2005. “RACE Battle Heads for City Council Vote.” Memphis Daily News. Retrieved May 3, 2010 from http://www.memphisdailynews.com/editorial/ ArticleEmail.aspx?id=28972\&print=1.

Mills, Charles W. 2001. "Black Trash.” In Laura Westra and Bill Lawson, eds., Faces of Environmental Racism: Confronting Issues of Global Justice. Second Edition. Lanham, MD: Rowman \& Littlefield.

Nussbaum, Martha. 1993. “Non-Relative Virtues: An Aristotelian Approach” in Nussbaum and Sen, eds. The Quality of Life. Oxford: Clarendon Press.

. 1999. “The Feminist Critique of Liberalism.” Reprinted in Steven Cahn (2005) , Political Philosophy: The Essential Texts. Oxford.

Sandler, Ronald. 2007. Character and Environment. New York: Columbia.

Shrader-Frechette. 2002. Environmental Justice: Creating Equality, Reclaiming Democracy. Oxford.

__ 2007. Taking Action, Saving Lives: Our Duties to Protect Environmental and Public Health. Oxford.

Slote, Michael. 2001. Morals from Motives. Oxford.

Swanton, Christine. 2003. Virtue Ethics: A Pluralistic View. Oxford. 
. 2009. "Heideggerian Virtue Ethics." Journal of Agricultural and Environmental Ethics 23 (1-2): 145-66.

Treanor, Brian. 2009. "Environmentalism and Public Virtue." Journal of Agricultural and Environmental Ethics 23 (1-2): 9-28

Van Wensveen, Louke. 2000. Dirty Virtues: The Emergence of Ecological Virtue Ethics. Amherst, NY: Humanity.

Welchman, J. 1999. “The Virtues of Stewardship.” Environmental Ethics 21 (4): 411-23. 